Alpysbes, A.M. \& Tukpatullin, T.S. (2020). Urbanization as a cultural process and a value phenomenon. Historical values and problems of their interpretation. Collection of Scientific Articles. European Scientific e-Journal, 5 (5), 1626. Hlučín-Bobrovníky: "Anisiia Tomanek” OSVČ. (in Russian)

Алпысбес, М.А., Тукпатул^ин, Т.С. (2020). Урбанизация как культурный процесс и ценностный феномен. Historical values and problems of their interpretation. Collection of Scientific Articles. European Scientific e-Journal, 5 (5), 16-26. Hlučín-Bobrovníky: “Anisiia Tomanek” OSVČ.

DOI: $10.47451 /$ his2020-12-002

EOI: $10.11244 /$ his $2020-12-002$

The paper is published in Crossref, Internet Archive, Google Scholar, Academic Resource Index ResearchBib, JGate, ISI, CiteFactor, ICI, eLibrary databases.

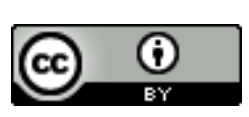

\author{
Mahsat A. Alpysbes \\ Professor, Doctor of History \\ Department of History of Kazakhstan \\ L.N. Gumilyov Eurasian National University \\ Nur-Sultan, Kazakhstan \\ E-mail: alpysbes@mail.ru
}

Timur S. Tukpatullin

Lecturer, Master of History

Department of Humanities

Z. Aldamzhar Kostanay Social and Technical University

Kostanay, Kazakhstan

E-mail: tukpatullin@mail.ru

\title{
Urbanization as a cultural process and a value phenomenon (in Russian)
}

\section{Abstract.}

Urbanization and scientific and technological progress have increased the influence of the new social reality on the individual and society. There comes a historical period when the absolute majority of citizens of the entire planet will live in cities, which in itself is a global phenomenon. This will lead to a fundamental revision of the urban mentality, which is currently experiencing a period of strong influence of the outgoing traditional thinking. The article reveals the topic of the influence of urbanization on the formation of cultural and axiological aspects of mentality. The article discusses the issue of positive and negative changes occurring in the way of thinking of newly arrived urban residents, and inconsistencies in understanding between the rural and urban worldview. The actors of the formation of urban culture and values are considered, as well as the prospects for their further development. The author concludes that the clash of values of traditional society and urban society can be compared with the clash of the cults of tradition and the cult of innovation. These two main components of human psychology change places in the course of urbanization. It becomes obvious that the process of urbanization is not unlimited.

Keywords:

urbanization, culture, values, city, mentality.

Махсат Анпысбесұмы Анпысбес Аоктор исторических наук профессор кафелры

Кафедра Истории Казахстана

Евразийский национальный университет им. $\Lambda . Н$. Гумилёва 
Нур-Султан, Казахстан

E-mail: alpysbes@mail.ru

\section{Тимур Сагингамиевич Тукпатуминн} магистр истории преподаватель кафедры

Кафедра гуманитарных наук Костанайский социально-технический университет им. 3. А^Аамжар

Костанай, Казахстан

E-mail: tukpatullin@mail.ru

\section{Урбанизация как кумьтурный процесс и ценностный феномен}

\section{Aннотачия:}

Урбанизация и научно-технический прогресс усилили вАияние новой социальной реальности на личность и общество. Наступает такой исторический период, когАа абсолютное большинство гражАан всей планеты будет проживать в городах, что само по себе является глобальным феноменом. Это приведёт к фундаментальному пересмотру городской ментальности, в данный момент переживающей период сильного влияния уходящего традиционного мышления. В статье рассматривается вопрос влияния урбанизации на формирования культурных и аксиологических аспектов менталитета. ОбсужАается мнения и взгляды об изменениях, происходящих в сознании жителей сменивших место жительства и прибывших Аля проживания в городскую среАу, разАичия в ментальности сельского и городского населения. Рассматриваются субъекты формирования урбанистической культуры и ценностей, её влияние на развитие общества и государства, науку, технологии и инновации а также перспектива их дальнейшего развития в суловиях процессов мегаполисизации. Автор делает заключение, что столкновение ценностей традиционного общества и урбанистического общества, можно сравнить со столкновением культов традиции и культа новаторства. Эти два главных составАяющих человеческой психологии меняются местами в ходе урбанизации. Становится очевидно, что процесс урбанизации небезграничен.

Клточевые слова:

урбанизация, культура, ценности, город, менталитет.

\section{Введение}

Урбанизация и научно-технический прогресс усимили вАияние новой социальной реальности на мичность и общество. Наступает такой исторический период, когда абсолютное большинство гражАан всей планеты будет проживать в городах, что само по себе является глобальным феноменом. Это приведёт к фундаментальному пересмотру городской ментальности, в Аанный момент переживающей период сильного вАияния уходящего траАиционного мышления.

Существует целый рял работ иностранных исследователей, в которых постав ена данная тема раскрывается, например, в таких как Шарон А. Зукин «Культуры городов»; Чарльз Аэндри «Креативный город», где он анализирует развитие культуры современного технологического общества в эпоху постмодернизма; также написанная совместно с Марком Пахтером книга «Культура 
на перепутье» о перспективах развития городской культуры. ВзгляА Аэвида Хезмондалша о формировании корпорациями общественного мнения городской среды раскрывается в книге «Культурные индустрии». В работе Уильям Митчель «Я, плюс-плюс: Человек, город, сети» он затрагивает передовой вопрос в ияния

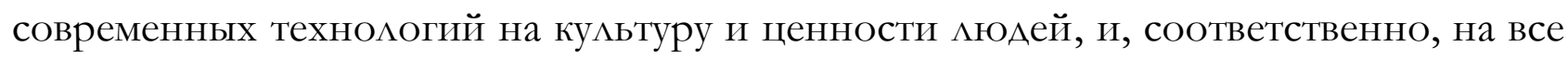
процессы глобализации.

Результаты исследования могут быть использованы в анализе аксиологических процессов городской среды коммерческим и государственным секторами, а также в планировании схожих исследований по теме культуры урбанизации.

Предметом исследования являются городская среда и урбанизационные процессы на нынешний период времени.

Цель исследования заключается в определении влияния урбанизации на общественную культуру и ценности. Из постав енной цели были сформулированы задачи:

1) определить нынешнее влияние городской среды на новоприбывших горожан и выявить вероятностные изменения в ментальных директивах;

2) выяв ение причин формирования данных культурных установок и перспектив их дальнейшего развития.

Урбанистическую культуру можно подразделить на 4 условных этапа его развития. На первом этапе городская культура выглядела как доиндустриальная земледельческая культура, с Аобавлением властных, ремесленных и торговых функций. На втором этапе происходит индустриализации, с середины XIX века и горожане получают возможность более интенсивного развития в социальном, политическом, культурном, образовательном отношении. На третьем этапе урбанистическая культура начинает транслироваться на всё общество в целом, благодаря Аостижениям научно-технического прогресса, начиная со второй половины ХХ века. Некоторые аграрные страны мира проходят этот этап только в настоящий момент (Барышева, 2015). На последнем, постурбанистическом этапе во главу угла становится креативный потенциал общества, который формирует и развивает высокотехнологичную информационную культуру, и она совершенно стирает барьер между городом и сельской местностью, создавая единое культурное пространство.

\section{1. ВАияние городской среды на мировоззренческие, ценностные и кумьтурные модели поведения новоприбывших горожан}

«Город - это антропогенная среда обитания, созданный человеком Аандшафт, где определены и обозначены культурные качества человека. С одной стороны, в городе человек создаёт сложную социальную и культурную реальность, отделяя 
себя от природы и подчиняя ее себе. С Аругой стороны, с появлением города человек вынужден существовать в определённых рамках и условиях, которые неявным образом изменяют его собственную природу» (Акалелова, 2014).

Урбанизация способствова^а изменению восприятия самоидентичности. Покилая привычную среду обитания, в которой всё расписано более традиционным мышлением и попадая в городскую среду, которая изобилует всевозможными сценариями поведения, ценностей, мировоззрения, палитрой разных субъективных реальностей индивид понимает, что окружение и происхождение, имеют вАияние на его судьбу, но определяющее значение играет осознанный выбор одной из этих

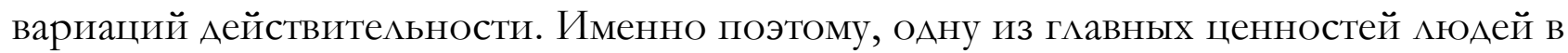
период миграции и урбанизации можно условно обозначить мозунгом «Стань кем хочешь стать».

Помимо этого город способствует как положительном так и отрицательным изменениям в мышлении пришлых граждан. Самой заметной является воспитательная функция, осуществляемая посредством контакта с новым окружением, которая подстраивает индивида под соблюдения необходимого культурного минимума. Следующая функция - культурно-информационная. БАагодаря ей индивиА приобщается к культурным событиям, становится получателем, транслирует сам значительно больший поток информации. Из этой функции вытекает следующая функция - социально-коммуникационная, в которой инАивиА контактирует со значительным количеством АюАей, за счёт повышенной плотности населения городов. Последней, но одной из определяющих в судьбе инАивида является образовательная функция. Город - это центр знаний и развития тесной социальной коммуникации. Получение акаАемического образования, профессиональных навыков и опыта работы во многих сферах становится доступно в городе (Акалелова, 2014).

Стоит отметить, что скорость аАаптации к урбанистической культуре зависит от возраста конкретного человека. Чем моложе - тем выше адаптация, и наоборот.

Из негативных функций города можно вылелить значимые изменения в социальном поведении новоприбывших горожан, такие как:

1. Рост безразличие к проблемам и событиям не имеющим непосредственное отношение к индивиду. При первом контакте с городской безАикостью, это

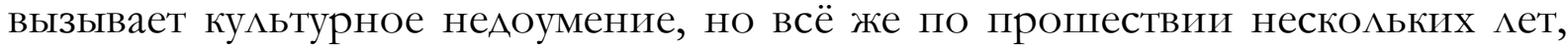
происходит аАаптация.

2. Коммуникативный ценз, который проявляется в значительно большей избирательности в общении, что обусловлено множеством контактов с Аюдьми. КажАый горожанин наблюдает вокруг себя, помимо большого числа незнакомцев, одних и тех же Аюдей, с которыми он виАится или 
взаимодействует по необходимости. Пример: сосеАи, колмеги, продавцы, пассажиры автобусов и т.А. И здесь наблюдается противоречие и разночтение в установках. В селе, неформальные отношения с окружающими - это норма поведения, так как там стоит вопрос взаимодействия и взаимопомощи стоит более остро в силу более экстремальных условиях. В городе - Аопустимо, но не столь необходимо. Во главе угла ставиться не создавать окружающим проблем и не навязывать свое общение, так как вопрос регулирования времени и тайм-менеджмент актуализиурется в условиях городской суеты.

3. Снижение авраженности реагирования на социацьную ответственность, по причине большей отстраненности в условиях города. Это сказывается на проблемах с оказанием помощи посторонним Аюдям.

4. Снижение объёма доверительных отношений, с преобладанием более формальных, что повышает риск одиночества. Как ни странно, но в больших городах количество доверительных связей на человека, существенно ниже чем в селах. Это объясняется более Аифференцированной системой взаимоотношений, чем в селе (Аончевский и Ар., 2016).

Помимо ценностных и поведенческих изменений, существуют культурные риски. Аля представителей народов, чья языковая и культурная идентичность находится под опасностью исчезновения, миграция в города с иноязычным общением означает снижение использования родного языка и смешанной самоидентичности, не говоря уже о снижении рождаемости начиная со второго поколения горожан (Ефимов и Ар., 2015).

Также в крупных городах происходят две противоположные тенденции в восприятии городской жизни. ОАна их часть стремиться стать в составе обособленной группы, объединенной по определённому признаку (кондоминиумы, анклавы, религиозные приходы, постоянные посетителей концертов, ресторанов; трудовые коллективы, клубы по интересам и т.А.), за пределами которой находится безАикий городской массив.

Эта обособленность близка к «домашним» городкам с небольшим населением, в которых практически все Аюди знают или имеют представление о Аруг Аруге. Психологически, это способствует обеспечению чувства безопасности, защищенности и причастности. Но отличие заключается в том, что жители небольших городов вынуждены Аовольствоваться ограниченным выбором возможностей своего города, в том время как члены обособленных групп мегаполисов, пользуются всеми привилегиями крупного города, стремясь минимизировать его безразличность и безликость (Фролов и Суходольская, 2010).

Вторая часть горожан напротив стремится к разнообразию типов общения, к новым АюАям и постоянно меняющимся тенденциям. Они чувствуют себя 
защищено в толпе прохожих, отчасти потому что правица взаимодействия в толпе

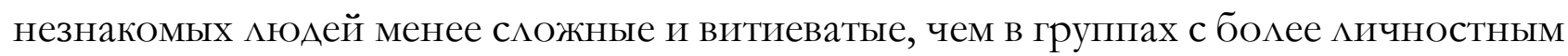
общением. Возможно, стремление жителей сёл и малочисленных городов к переезАу в мегаполисы обусловлены именно таким типом мышления. ВеАь, помимо прочего, близкое общение в обособленных группах мегаполисов, в сообществе сёл и в «Аомашних городках» предъявляет требования к поведению всех её членов. Чтото осуждается, а что-то поощряется. В крупных городах практически нет поведенческого ценза, не считая радикального и опасного Аля общества поведение.

В современном мире, всё чаще наблюдается такие яв ения как дауншфтинг, рурбанизация и субурбанизация. Горожане обуславливаясь мичными мотивами переезжают в Аеревню, небольшой город или пригород, гАе жизнь протекает без суеты мегаполиса в размеренном ритме. Это также объясняется снижением стресса («поближе к природе»), который оказывает город на индивида и снижением финансовых расходов на проживание (Рабкин, 2015).

Согласно проведенным исследованиям ростовских ученых в области постурбанистики к важнейшим изменением в ценностях относятся: «...ценность уникализации, приходящая на смену ценности унификации; ценность современного семейного трудо- и бытоустройства, замещающая ценность фабрично-заводской отчужденности; ценность человекоцентристского технологического и социально-бытового уклаАа, конкурирующего с приоритетами машинного производства и стандартами потребления, ценность социацьного капитала в противоположность городской разобщенности» (Аончевский и Ар., 2016).

Таким образом, ментацьные изменения в жизни новоприбывших горожан, протекают на фоне меняющегося культурного-аксиологического фундамента урбанизации. В целом, переезА в город сказывается положительно, плюсы превышают минусы. К тому же миграция из сёл в города обусловлена Авумя наиболее частыми мотивами: вынужденная миграция, когда в прежнем месте проживания нет возможности получить образование, нет перспективы Аля себя или детей, безработица или угроза потери работы в будущем; мотивированная миграция, когАа уровень жизни в месте проживания удовлетворяет жизненные потребности, но переезА сулит большую самореализацию. В обоих случаях, есть больше вероятности улучшить свою жизненное положение.

\section{2. Акторы формирование культурной и ценностной идентичности}

Началом исследования влияния урбанизации на общество было положено в конце XIX века, когда европейские нации столкнулись с кризисами разрастающихся индустриальных городов. И происходящее стало объясняться 
особым статусом города как социацьно-природного образования, живущего по внутренним законам (Рой и Чуканов, 1997).

Реакцией на кризис стало широкое распространение инновационных илей в градостроительстве, а вместе с тем выбор направления развития культуры городов. ОтАельный вопрос о положении городских посёлков и малых городов.

В начале XX века, периол начала противостояния капиталистических и социалистический идей общественного мироустройства многие преАложения касательные решения социально-культурных проблем горожан, выАвигались именно представителями этих двух полярных точек политических мировоззрений.

В Европе становились популярны илеи жилья, в котором жители города могли более теснее контактировать Аруг с Аругом, трудиться, воспитывать и обучать Аетей и т.А. ИнАивиАуальный мир стал ближе к колцективному. Это ставило по-новому вопрос об архитектуарных структурах городов.

Ощущая потребность в простом и оригинацьном решении архитекторы того времени, вАохновленные социалистическим экспериментом преАлагали свои илеи по формированию городов, в которых АОАжны будут жить АюАи нового социалистического мышления.

Так Тони Гарнье - отец градостроительного зонирования, выАвигац свою илею как будущее городского расположения кварталов, что в свою очереАь Аолжно было способствовать более рациональному жизненному уклалу. Он предложиц создать экспериментальный город во Франции, где все постройки будут продуктом массового строительства бюджетного жилья, поделенного на зоны проживания и Аосуга, аАминистративную, производственную и сельскохозяйственную зоны. Интересно что по его замыслу в городе не Аолжно было быть места Аля духовных заведений и органов правопорядка. По его мнению, социализм был способен так поднять самосознание горожан, что в них просто не было необходимости. Это

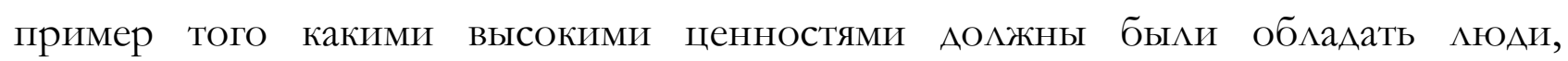
преАположительно, в обозримом будущем.

Схожих с Гарнье илей придерживался всемирно известный архитектор, новатор, создатель архитектурного модернизма и функционализма Шарль ЭдуарА Жаннере-Гри, более известный под псевдонимом «Ае Корбюзье». Его идеи во много определили архитектуру ХХ века, стали революционными Аля передовых стран мира и к тому же из-за его его политических предпочтений, $е$ Корбюзье пользовался популярностью в СССР. Отчасти его проект «Аучезарного города» узнаваем во многих городах постсоветского пространства. По мнению архитектора социалистическое общество, проживающее в городах будущего, Аолжно было изжить многие недостатки человечества, при помощи широкомасштабной системы рационального жизненного планирования начиная от многоступенчатого 
государственного воспитания Аетей заканчивая тотальным контролем наА экономикой. Предположительно городское население Аолжно было последовательно проходить по всем степеням осознания рациональной реальности, в конце которой принятие полного социального планирования было неизбежным. Города $е$ Корбюзье были верхом унификации, что в свою очередь требовалось и от её жителей.

Совершенно противоположных мыслей придерживался один из сильнейших архитекторов США, человек широких новаторских взглядов Фрэнк А^ойА Райт, придерживавшийся сильных капиталистических позиций. Он считац что хозяином жилья может быть только тот человек, который обладает Аомом на земле, и является владельцем земельного участка, потому что жизнь в многоквартирных домах - это

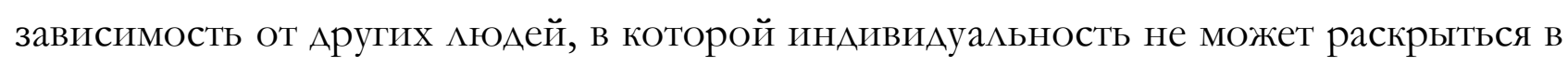
полной мере. По этой причине он продвигал идею качественного, но не «штампованного» жилья. Его илея широкой застройки пригородной территории Аомами на одну семью стали очень популярны в периол после Второй мировой войны. СолАаты демобилизовавшись подпаАали под государственную программу мьгот “ВI Вill” согласно которой они могли на выходных условиях получить кредит на строительство дома в пригороде, получить образование и получать пенсию ветерана. Эта илея во многом определила нынешний облик США, потому что необходимость добираться до работы из пригорода стимулировацо покупку машины, что в масштабах страны привело к автомобильному буму в стране. Увеличение значения частного транспорта сократило значение общественного. Вся Америка покрылась широкими автомагистралями, эстакадами и прочей дорожной инфраструктурой. Но культурно это сказалось на ощущении Аичной свободы и независимости, что подтвердицо умозаключения Ф.А. Райта (Костарев, 2012).

К тому же США, являясь ядром капиталистического магеря, не могли себе позволить заигрывание с социалистическими идеями Аоступного унифицированного жилья Аля всех гражАан, активно возводимого в странах социалистического магеря.

В данный же период времени европейские стран, страны Северной Америка, Японии, Корее и Автралии стали развивать постурбанистические направления развития общества. Во главу угла встают творческие направ ения развития, на стыке которых появАяются креативные подходы к экономической и культурной деятельности города (арт-сквоты, коворкинги, бизнез-инкубаторы и smartтерритории). Постурбанизм определяет уход фокуса от промышленных подхода к многообразию различной деятельности, удовлетворяющей все потребности общества. Таким образом расширяется ресурсная база Аля развития города, 
создается конкуренция экономических стратегий, широкий спектр трудоустройства Аля молодежи (Аробышева, 2016).

Креативность в современной городской среде - это одна из кАючевых аксиологических координат в жизни общества. Необычный, оригинацьный творческий подход - это то что уже сейчас показывает свою эффективность на примере успехов «икон кремниевой Аолины» таких как Стив Ажобс (основатель Apple), Бил Гейтс (основатель Microsoft), Марк Цукерберг (основатель Facebook), Ян Кум (основатель WhatsApp). Ао того как их продукт стал популярным

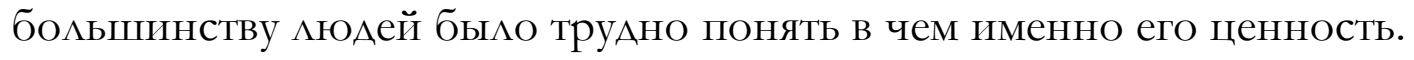

Таким образом, начало ХХ века было обусловлено формированием у населения разных политических блоков илеологического воспитания, а урбанистическая культура формировалась как следствие этих иАеологий. В капиталистических странах помимо государственной идеологии остаются сильными методы корпораций по регулированию потребительского поведения. Вероятнее всего, что в XXI веке благодаря вызвышении ценности креативности и творческого подхода уже не столько государства и организации будут направлять развитие культуры городов, сколько креативные группы самих гражАан. ЗАесь как никак к месту будет высказывание Остина Клеона: «Все, что вы должны сделать, - это показать всем своно работу» (Кıеон, 2014).

\section{Закмючение}

Таким образом, столкновение ценностей традиционного общества и урбанистического общества, можно сравнить со столкновением культов традиции и культа новаторства. Эти Ава главных составляющих человеческой психологии меняются местами в ходе урбанизации. Во главу угла встаёт креативность и оригинальность, новизна решений. Консерватизм слаёт позиции, но не уходит совсем, по причине ограниченности восприятия человеческим обществом новых

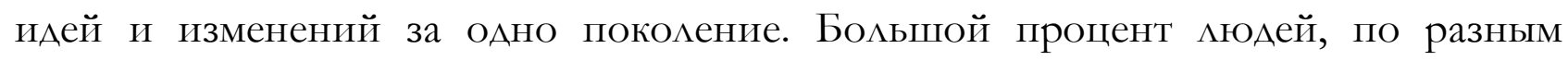
причинам переселяются в города, тем самым меняют свой привычный образ жизни и мировоззрения на тот в котором собираются прижиться. Это вносит в их жизнь необходимость смириться с изменениями, если переезА в город вынужденная мера, и искать в нем позитивные стороны. То есть, вилеть в «новом» - благое.

Тем самый мы подтвердили важность изучаемой проблематики, изучили историки, нынешнее состояние и перспективы Аальнейшего развития.

Становится очевидно, что процесс урбанизации небезграничен. ОАнажды, достигнув предела в соотношении «село - город», вероятнее всего свыше 90\% населения будут жить в городах. Система стабилизируется и придёт череА её консервации, что подразумевает поА собой создание культуры, способной 
просуществовать значительное количество времени, эффективно выполняя функцию регулятора жизни общества в новом урбанизированном мире. Ао наступцения этого момента Аолжны появ яться всевозможные вариации этой культуры из которых, естественным путём сохраняться самые эффективные. Они и будут определять жизнь общества в булущем. Вполне возможно, что после нескольких веков бурной новаторской деятельности начиная с промышленной революции XIX века, у человечества наступит «инновационные каникулы», в течении которых система культуры не будет меняться значительным образом по причине отсутствия необходимости.

\section{Список источников информации:}

Акалелова, Т.А. (2014). Антропологические характеристики урбанистической культуры. Исторические, философские, политические и юридическе науки, культурология и искусствоведение. вопросы теории и практики, 6-1 (44), 13-15. Тамбов: Изаательство «Грамота».

Барышева, В.В. (2015). Формирование культурной идентичности современного города. Научно-методический электронный журнал «Кончепт», 30, 146-150.

Аончевский, Г.Н., КАименко, А.В., Ермишина, А.В. (2016). Ценностные основания институционализации постурбанистических образований в России: гипотеза и результаты эмпирических исследований. Journal of institutional studies (Жyрнал институциональных исследовании), 8, 1, 72-84.

Аробышева, Е.Э. (2016). Ценностные стратегии культурных индустрий. Международный журнал исследований культуры, 2 (23), 106-114. Санкт-Петербург: ООО «ЭйАОс».

Ефимов, В.С., Ааптева, А.В., Михайлова, Е.И. (2015). ВАияние урбанизации на процессы сохранения культуры и языка народа саха: социологический анализ. Археология, этнография и антропология Евразии, 43, 4, 127-134.

Клеон, О. (2014). Покажи свою работу! Аесять способов сделать так, итобъ тебя заметили. Москва: Манн, Иванов и Фербер.

Костарев, С.В. (2012). У рбанизация как фактор динамики культуры. Омский научнъгй вестник, 5 (112), 233-236.

Рабкин, В.С. (2015). Влияние городского пространства на культурную илентификацию человека в современном обществе. Международный научноисследовательский журнал, 8(39), 13-14.

Рой, О.М., Чуканов, С.Н. (1997). Город как предмет экономической и сочиально-экологической оченки: Монография. Омск: Иза-во ОмГТУ. 
Фролов, А.А., Суходольская, Н.П. (2010). К феноменологии городского пространства. Вестник МГСУ, 4-3, 394-399. 